\title{
Gaya Hidup Hedonisme Mahasiswa Pascasarjana di Media Sosial
}

\author{
Elia Firda Mufidah ${ }^{1}$, Peppy Sisca Dwi Wulansari ${ }^{2}$ \\ Pascasarjana Universitas Negeri Malang ${ }^{1 \& 2}$ \\ Email: peppysisca@gmail.com ${ }^{2}$
}

\begin{abstract}
:
Graduate students are in early adulthood at the age of 18 to 40 years. As adolescence moves into adulthood, adulthood (emerging adulthood) is marked by experimentation and exploration. Hedon lifestyle can not be separated from the world of students. Students tend to have a hedon lifestyle in order not to be labeled obsolete or old age kids. This research uses qualitative research with case study type with research subject of guidance and counseling students of State University of Malang class of 2016. The conclusion shows that graduate student has a hedonism lifestyle is done to get pleasure so that encourage them to complete their duty.
\end{abstract}

Keyword: Graduate Students, Hedonisme

Received February 01, 2018; Revised March 02, 2018; Accepted April 01, 2018

How to Cite: Mufidah E. F., \& Wulansari P. S. D. (2018). Gaya Hidup Hedonisme Mahasiswa Pascasarjana di Media Sosial. JKI (Jurnal Konseling Indonesia), 3(2), 33-36.

This is an open access article distributed under the Creative Commons 4.0 Attribution License, which permits unrestricted use, distribution, an reproduction in any medium, provided the original work is properly cited. @2018 by author and Universitas Kanjuruhan Malang.

\section{PENDAHULUAN}

Kemajuan teknologi membuat kemajuan dibidang komunikasi yang dapat membantu manusia berinteraksi satu sama lain tanpa batas tempat atau waktu (Widiantari \& Herdiyanto, 2013). Pada arus globalisasi di zaman ini, perkembangan teknologi sangat pesat. Banyak sosial media yang bisa diakses dengan mudah oleh setiap orang. Mahasiswa yang dalam tahapan ini memiliki rasa ingin tahu yang tinggi maka dengan mudah untuk bisa menggunakan sosial media yang paling up to date. Dengan sosial media yang berkembang saat ini, individu difasilitasi untuk bisa menunjukkan dirinya untuk menjadi pusat perhatian atau "center of attention". Salah satu contohnya dengan adanya ig atau Instagram, individu bisa memposting apa yang terjadi dalam dirinya dan menarik perhatian orang untuk memberikan comment atau komentar.

Perkembangan media sosial mendorong individu untuk cenderung ingin menunjukkan dirinya dengan cara menjadi "center of attention" atau pusat perhatian. Media sosial yang memfasilitasi berbagai kemudahan mengekspose kegiatan individu. Seperti halnya Instagram yang memiliki fasilitas berbagi cerita kegiatan yang sedang dilakukan baik berupa video ataupun gambar. Tidak sedikit mahasiswa yang hampir setiap hari memposting video kagiatannya terutama ketika mereka nongkrong di kafe ataupun sedang mengerjakan tugasnya sebagai salah satu indikator gaya hidup hedonisme. Selain itu melalui media sosial terbentuk komunitas online yang meningkatkan nilai konsumtif dalam diri individu (Nalewajek \& Macik, 2013). Hal tersebut terjadi karena dalam suatu komunitas individu cenderung untuk menampakkan apa yang dimilikinya, baik berupa pakaian maupun gaya hidup. 
Mahasiswa cenderung memiliki gaya hidup hedon agar tidak dicap ketinggalan zaman atau kids zaman old. Sebagai bentuk aktualisasi agar tidak ketinggalan zaman mereka memposting aktivitas mereka yang berpindah-pindah tempat nongkrong maupun bergonta-ganti pakaian yang bermerk di sosial media. Padahal sejatinya masih banyak dari mereka yang menggunakan uang dari orang tua untuk menyalurkan gaya hidup hedonisme mereka.

Terlebih lagi mahasiswa pascasarjana bimbingan dan konseling. Sejatinya konselor akan menjadi model untuk siswanya ketika terjun di sekolah maupun ketika terjun menjadi dosen. Hedonisme merupakan prinsip pribadi individu (Umami, 2013). Ketika individu memilih suatu prinsip dalam hidupnya maka prinsip tersebut akan berpengaruh terhadap kehidupan mereka termasuk penilaian baik dan buruk.

\section{METODE PENELITIAN}

Penelitian kualitatif menurut Bogdan dan Taylor (Moleong, n.d.) merupakan prosedur penelitian yang menghasilkan data deskriptif berupa kata-kata tertulis atau lisan dari orang-orang dan perilaku yang dapat diamati, dan pendekatan ini diarahkan pada latar serta individu tersebut secara holistic atau utuh. Penelitian ini menggunakan penelitian kualitatif dengan jenis studi kasus.

(Shaughnessy, Zechmeister, \& Zechmeister, 2007) menjelaskan bahwa penelitian studi kasus merupakan titik awal bagi peneliti yang sedang memasuki bidang penelitian yang masih relative sedikit diketahui. Berdasarkan pada fenomenna atau gejala yang muncul yaitu masalah mahasiswa yang memiliki gaya hedonism kemudian ditampilkan di media sosial.

\section{HASIL}

Hasil penelitian diperoleh melalui observasi, wawancara dan dokumentasi. Data yang diperoleh dalam penelitian ini bersumber dari informan yang berjumlah empat orang. Informan tersebut adalah mahasiswa dan mahasiswa pascasarjana bimbingan dan konseling Universitas Negeri Malang. Adapun profilnya dapat dilihat pada tabel 1

Tabel 1. Profil Subjek yang Terlibat Gaya Hidup Hedonisme

\begin{tabular}{cccc}
\hline No & Nama & Usia & Alamat \\
\hline 1 & EF & 23 & Gresik \\
\hline 2 & PN & 27 & Banten \\
\hline 3 & KL & 23 & Lamongan \\
\hline 4 & MZ & 23 & Madura \\
\hline
\end{tabular}

EF merupakan anak pertama dari tiga bersaudara, EF berasal dari kota Gresol. EF saat ini berusia 23 tahun, dengan tinggi badan kurang lebih $165 \mathrm{~cm}$, berkerudung dan memakai kacamata. EF memiliki latar belakang pernah bekerja di kampus saat dia sedang menempuh kuliah S1 nya. Ketika dilakukan wawancara EF terlihat menjawab semua pertanyaan dengan santai.

EF tertarik dengan gaya hidup hedon sejak S1. Menurutnya gaya hidup hedon dilakukan sesuai dengan kondisi keuangannya. EF memiliki pandangan bahwa gaya memakai pakaian yang branded bisa membuat nyaman dirinya. Selain itu, nongkrong yang dilakukannya tidak terjadual yang artinya dia bisa nongkrong semaunya. EF merasa nongkrong bisa mengurangi tingkat stress yang diamalinya. Ketika tugas kuliah sudah banyak maka EF akan mencari hiburan dulu dengan nogkrong ataupun berbelanja bbarang-barang branded. Baginya hedonism sah-sah saja dilakukan oleh semua orang jika dia mampu untuk melakukannya.

Jika diamati dalam akun Instagram yang dimilikinya ada beberapa postingan foto yang menunjukkan posisi dimana dia nongkrong. Selain itu, EF mengaku suka memposting status video di Instagram pada saat dia nongkrong untuk menunjukkan tempat makan yang pernah dicobanya.

PN merupakan anak pertama dari 3 bersaudara. PN berasal dari Banten dan sekarang tinggal di kos di area dekat dengan MATOS. PN memiliki tinggi sekitar $160 \mathrm{~cm}$ dan berwarna kulit sedikit gelap. PN memiliki latar belakang pernah tingal di pondok pesantren.

PN mulai tertarik dengan gaya hidup hedon semenjak dia kerja. Gaya hidup hedonnya terjadi ketika teman-teman satu kantornya mengajaknya untuk melakukan hal tersebut seperti nongkrong ataupun membeli barang-barang yang branded. Kebiasaan itupun dibawanya sampai sekarang melanjutkan kuliah diperguruan 
tinggi pascasarjana. PN mengaku menyukai nongkrong, bisa jadi dalam seminggu PN bisa nongkrong terjadual minimal 1 kali untuk menghilangkan stress dan mencari hiburan disaat tugas kuliah menumpuk. Hal tersebut dianggapnya sah-sah saja ketika keuangannya bisa memenuhi gaya hidupnya. Terutama dalam hal berpakaian. Menurutnya dia akan membeli pakaian yang tidak "pasaran" dalam artian pakaian yang tidak banyak dimiliki oleh orang lain.

Jika diamati dalam akun media sosialnya, ada beberapa foto PN yang menunjukkan keberadaannya saat nongkrong dan pergi ke tempat yang sedang menjadi trend atau kekinian. PN mengaku tidak begitu suka memposting gaya hidupnya di media sosial karena dia pernah menjadi guru.

KL merupakan anak pertama dari tiga bersaudara. KL memiliki tinggi sekitar $170 \mathrm{~cm}$. Selain menjadi mahasiswa pascasarjana, KL menjadi guru di salah satu sekolahan di daerah asalnya. Sehingga KL harus pulang pergi untuk menempuh kuliah dan mengajar.

Gaya hidup hedonnya diakui terjadi semenjak dia masuk bangku kuliah S1 karena faktor banyaknya tugas sehingga dia membutuhkan cara agar tidak stress dan tugasnya bisa selesai. Baginya salah satu barang yang wajib dengan merk tertentu yakni sepatu yang dikenakannya. Jika diamati di media sosial instagramnya, KL tidak pernah memposting gaya hidup hedonnya. KL mengaku tidak suka memposting aktivitasnya di media sosial karena banyak siswanya yang bisa melihatnya.

MZ merupakan anak pertama dari dua bersaudara. MZ memiliki tinggi badan sekitar $170 \mathrm{~cm}$. MZ berasal dari Madura dan sekarang tinggal di kos dengan adeknya yang sudah selesai menempuh jenjang S1 nya. Selain menjadi mahasiswa pascasarjana, MZ juga bekerja di sekolah sehingga MZ harus tiap minggu pulang pergi dari Madura.

MZ memiliki gaya hidup hedon dalam hal nongkrong. MZ mengaku tugas kuliahnya cepat terselesaikan jika dia mengerjakannya dengan nongkrong. Baginya nongkrong memberikan insirasi tersendiri untuk tugastugasnya. Selain itu untuk barang-barang yang dimilikinya ada brand tertentu yang disukainya.

Jika diamati di media sosial instagramnya, MZ memiliki aktivitasnya. Selain itu ada foto brand dari barang yang disukainya. MZ sering terlihat memposting video yang menunjukkan aktivitasnya nongkrong sambal mengerjakan tugas.

\section{PEMBAHASAN}

Berdasarkan hasil yang telah dipaparkan, maka hasil penelitian dapat disimpulkan bahwa setiap individu berpotensi untuk bergaya hidup hedonisme. Gaya hidup hedonism dipengaruhi oleh lingkungan mereka terutama lingkungan kerja. Selain itu untuk mahasiswa pascasarjana, gaya hidup hedonism mereka dipengaruhi oleh tingkat stress dalam mengerjakan tugas karena sebagian dari mereka selain menjadi mahasiswa juga bekerja. Seperti halnya (Heathwood, 2006) mengungkapkan bahwa hedonism menjurus kepada kehidupan yang menyenangkan.

Individu dengan gaya hidup hedonis cenderung memiliki nilai kenikmatan, harta benda, dan hiburan. Konsisten dengan nilai-nilai, individu cenderung terlibat dalam kegiatan seharihari yang menekankan konsumsi dan kenikmatan (Kunzmann, Stange, \& Jordan, 2005). Hal tersebut yang menjadi faktor eksternal sehingga mereka memiliki gaya hidup hedonism. Gaya hidup hedonisme yang diposting di media sosial memiliki unsur pengakuan dari gaya hidup yang mereka miliki. Seperti halnya penelitian dari (Puspitasari, 2015) mengemukaka bahwa kebutuhan yang mendorong individu untuk memposting disalah satu media sosial yakni faktor eksplanasi diri, kebutuhan untuk mendukung orang lain, tampil baik dan kebutuhan untuk menjalin relasi dengaan orang lain.

Kesimpulan lain dari hasil wawancara didapatkan bahwa gaya hidup hedonisme menjadi hal yang wajar dilakukan ketika individu memiliki keuangan yang cukup mendukung untuk mereka melakukan hal tersebut.

\section{SIMPULAN DAN SARAN}

Berdasarkan hasil yang telah dipaparkan, maka hasil penelitian dapat disimpulkan bahwa setiap individu berpotensi untuk bergaya hidup hedonisme. Gaya hidup hedonism dipengaruhi oleh lingkungan mereka terutama lingkungan kerja. Selain itu untuk mahasiswa pascasarjana, gaya hidup hedonism mereka dipengaruhi oleh tingkat stress dalam mengerjakan tugas karena sebagian dari mereka selain menjadi mahasiswa juga bekerja. Seperti halnya (Heathwood, 2006) mengungkapkan bahwa hedonism menjurus kepada kehidupan yang menyenangkan.

Individu dengan gaya hidup hedonis cenderung memiliki nilai kenikmatan, harta benda, dan hiburan. Konsisten dengan nilai-nilai, individu cenderung terlibat dalam kegiatan seharihari yang menekankan 


\section{Jurnal Konseling Indonesia}

http://ejournal.unikama.ac.id/index.php/JKI

ISSN: Print 2475-888X - Online 2476-8901

Vol. 3 No. 2, April 2018. hlm. 33 - 36

konsumsi dan kenikmatan (Kunzmann et al., 2005). Hal tersebut yang menjadi faktor eksternal sehingga mereka memiliki gaya hidup hedonism. Gaya hidup hedonisme yang diposting di media sosial memiliki unsur pengakuan dari gaya hidup yang mereka miliki. Seperti halnya penelitian dari (Puspitasari, 2015) mengemukaka bahwa kebutuhan yang mendorong individu untuk memposting disalah satu media sosial yakni faktor eksplanasi diri, kebutuhan untuk mendukung orang lain, tampil baik dan kebutuhan untuk menjalin relasi dengaan orang lain.

Kesimpulan lain dari hasil wawancara didapatkan bahwa gaya hidup hedonisme menjadi hal yang wajar dilakukan ketika individu memiliki keuangan yang cukup mendukung untuk mereka melakukan hal tersebut.

\section{DAFTAR RUJUKAN}

Heathwood, C. (2006). Desire satisfactionism and hedonism. Philosophical Studies, 128(3), 539-563.

Kunzmann, U., Stange, A., \& Jordan, J. (2005). Positive affectivity and lifestyle in adulthood: Do you do what you feel? Personality and Social Psychology Bulletin, 31(4), 574-588.

Moleong, J. (n.d.). Lexy. 2014, Metodologi Penelitian Kualitatif, Bandung: PT. Remaja Rosdakarya.

Nalewajek, M., \& Macik, R. (2013). The impact of virtual communities on enhancing hedonistic consumer attitudes. Zeszyty Naukowe Szkoły Głównej Gospodarstwa Wiejskiego W Warszawie. Polityki Europejskie, Finanse I Marketing, (10 [59]).

Puspitasari, F. I. (2015). Kebutuhan yang Mendorong Remaja Memposting Foto atau Video Pribadi dalam Instagram.

Shaughnessy, J. J., Zechmeister, E. B., \& Zechmeister, J. S. (2007). Metodologi penelitian psikologi. Edisi Ke-7. Yogyakarta: Pustaka Pelajar.

Umami, A. (2013). Hubungan antara harga diri dengan kecenderungan gaya hidup hedonis pada mahasiswi di Surakarta. Universitas Muhammadiyah Surakarta.

Widiantari, K. S., \& Herdiyanto, Y. K. (2013). Perbedaan intensitas komunikasi melalui jejaring sosial antara tipe kepribadian ekstrovert dan introvert pada remaja. Jurnal Psikologi Udayana, 1(1), 106-115. 